\title{
Experimental Study on Drag Reduction Characteristics of Bionic Earthworm Self-Lubrication Surface
}

\author{
Guomin Liu, ${ }^{1,2}$ Xueqiao $\mathrm{Wu}^{3}$ Meng Zou ${ }^{3},{ }^{3}$ Yuying Yan, ${ }^{2}$ and Jianqiao $\mathrm{Li}^{3}$ \\ ${ }^{1}$ College of Civil Engineering, Jilin Jianzhu University, Changchun 130118, China \\ ${ }^{2}$ Faculty of Engineering, University of Nottingham, University Park, Nottingham NG7 2RD, UK \\ ${ }^{3}$ Key Laboratory of Bionic Engineering, Jilin University, Changchun 130022, China \\ Correspondence should be addressed to Meng Zou; zoumeng@jlu.edu.cn
}

Received 24 June 2019; Accepted 20 September 2019; Published 23 October 2019

Academic Editor: Raimondo Penta

Copyright (C) 2019 Guomin Liu et al. This is an open access article distributed under the Creative Commons Attribution License, which permits unrestricted use, distribution, and reproduction in any medium, provided the original work is properly cited.

In the present study, a coupling bionic method is used to study the drag reduction characteristics of corrugated surface with lubrication. In order to test the drag reduction features, bionic specimen was prepared inspired by earthworm surface and lubrication. Based on the reverse engineering method, nonsmooth curve of earthworm surface was extracted and the bionic corrugated sample was designed, and the position of lubrication hole was established by experimental testing. The lubricating drag reduction performance, the influence of normal pressure, the forward velocity, and the flow rate of lubricating fluid on the forward resistance of the bionic specimens were analyzed through a single factor test by using the self-developed test equipment. The model between the forward resistance and the three factors was established through the ternary quadratic regression test. The results show that the drag reduction effect is obvious, the drag reduction rate is $22.65 \%$ to $34.89 \%$, and the forward resistance decreases with the increase of the forward velocity, increases with the increase of the normal pressure, and decreases first and then becomes stable with the increase of flow rate of lubricating fluid. There are secondary effects on forward resistance by the three factors, and the influencing order is as follows: normal pressure $>$ flow rate of lubricating fluid $>$ forward velocity.

\section{Introduction}

Soil adhesion is a major problem in the field of ground transportation, excavation, and farming machinery. The adhesion of soil to soil-engaging components will seriously affect the working efficiency and quality of ground machinery, thus increasing energy consumption [1-4]. With the aggravation of energy and environmental crises, it is imperative to design and produce soil-engaging components with high efficiency and low consumption. Earthworm is a typical soil animal, which has an excellent function of reducing drag and removing soil in long-term evolution. It can also move freely in clayey soil and does not have clay $[5,6]$. Since early 1990 s, scholars at home and abroad have gradually carried out bionic research on reducing soil adhesion and scouring soil of earthworm. Li et al. [7] carried out the extraction of earthworm surface fluid and studied the adhesion reducing the mechanism of earthworm surface self-lubrication. Sun et al. [8] measured the surface potential of earthworms; Ren et al.
$[9,10]$ put forward the surface electroosmosis technology according to the phenomenon of earthworm surface electroosmosis and applied it to soil-engaging components. In the late 1990s, Ren et al. [11] studied the surface flexibility of earthworms and their antiviscosity characteristics. After 2004, Sun et al. [12, 13] and Li et al. [14-16] have successively carried out biomimetic research on the viscosity reduction and drag reduction of earthworm's nonsmooth surface. Shi et al. [17] carried out a biomimetic study on earthworm telescopic motion. $\mathrm{Zu}$ and $\mathrm{Yan}[18,19]$ used the lattice Boltzmann method to simulate the surface electroosmosis of earthworms and further studied the adhesion reducing the mechanism of earthworm surface electroosmosis. These studies mainly focus on the unit biomimetic of a certain aspect or a certain factor.

With the deepening of bionic research, researchers have found that the functions, which biologically adapt to the external environment, are not only the role of a single factor or the simple addition of multiple factors but also the results 
of synergistic action that a variety of interdependent, mutually affecting factors are coupled through a certain mechanism $[20,21]$. The research shows that earthworm has an excellent function of viscosity reduction and drag reduction, which is the result of multifactor coupling action such as body surface structure, body surface flexibility, body surface electroosmosis, body surface lubrication, and its unique movement mode [22-25]. Based on the nonsmooth structure and the selflubricating characteristics of earthworm surface, this paper discusses the drag reduction characteristics of earthworm by a dual-coupling biomimetic method, in order to provide a new theory and method for the design of soil-engaging components with high efficiency and low consumption.

\section{Materials and Methods}

2.1. Coupling Bionic Sample Design. Earthworms are common animals that can move freely in the soil; it can adapt to different soil environments. The viscosity reduction ability of earthworms mainly depends on its flexible nonsmooth body surface, bioelectroosmotic system, surface lubrication, corrugated body surface, and other factors [12]. In this paper, Eisenia foetida was used as bionic prototype, and according to the previous studies, the corrugated body surface of earthworm has the characteristics of reducing viscosity and drag [21]. The effect of viscosity and drag reduction of the different states of the body from large to small is contraction state, motionlessness state, and stretched state, and the effect of viscosity and drag reduction of the head is more obvious than that of the body. Therefore, the head contraction state of earthworm has the best viscosity and drag reduction effect $[14,15]$, as shown in Figure 1(a).

Based on the reverse engineering method, the corrugated body surface of earthworm was scanned by a 3D laser scanner, and the data of point cloud was processed by Geomagic software. There are about ten knots involved in each extension-contraction movement of earthworms, the head and body are the main position of soil adhesion and force, and the tail are weak [14-16], so they are equivalent to a cylinder when designing biomimetic samples, composed of 10 body knots, and the tail curve is designed as the symmetrical curve of the head. Through the commands of three-point arc, tangent arc, and curve curvature extension in CAXA, the smooth curve which is close to the contour curve of the corrugated body surface of earthworm is drawn, and the coordinate point data of the smooth curve are extracted. Then, the spline curves of the head shape are drawn by using coordinate points. At last, amplifying the size by six times for engineering needs, the biomimetic sample was printed in 3D. As shown in Figure 1(b), the length is $207.18 \mathrm{~mm}$, the width is $62.59 \mathrm{~mm}$, the thickness is $31.28 \mathrm{~mm}$, the sample material is photosensitive resin, and the printing precision is $0.1 \mathrm{~mm}$. For comparative analysis, a smooth specimen of the same size was designed, as shown in Figure 1(c).

The lubrication hole's position of earthworm surface has direct influence on the lubricating effect [26], and the hole location of the corrugated surface sample is determined by the test method. According to previous studies, normal pressure is the most important factor affecting adhesion force. So, selecting the yellow clay of Changchun city, when the soil moisture content was $22.2 \%$ and the forward velocity was $200 \mathrm{~cm} / \mathrm{min}$, the experiment was carried out with five different normal pressure conditions, and each group was repeated three times. As shown in Figure 2, the adhesion was at a normal pressure of $34 \mathrm{~N}$.

The adhesion data is shown in Table 1. According to Table 1, there is more adhesion to the head and body, but there is no adhesion in the tail.

In order to prevent clogging, the bionic dorsal foramen was designed in the top of the sulcus of the head and body backward-forward direction according to the adhesion and model characteristics. They are including the anterior foramen of the head (HF), the posterior foramen of the head (HB), the anterior foramen of the body (BF), and the posterior foramen of the body (BB), as shown in Figure 3.

2.2. Test Rig and Methods. According to the test requirements, the test rig for lubricating and drag reduction performance of soil-engaging components was designed, as shown in Figure 4(a). The rig consists of support frame, soil bin, motion control device, data acquisition device, and lubrication adjustment device.

The soil is fixed on the support frame, and the motion control device is fixed directly above the soil bin, mainly including servomotor, pulley motion pair, and sliding plate, which is responsible for the bidirectional motion of the soil-engaging components in the soil bin. The lubrication adjustment device is fixed on the upper left side of the soil bin, mainly including peristaltic pump, peristaltic pump frame, and water tank, which can convey lubricating fluid during the movement of soil-engaging components. The pump is compiled by external software and connected to the computer. According to the conditions, the flow rate can be set and the number of the opening pump and the lubricating position can also be set, so that the flow rate can be accurately adjusted. The data acquisition device is fixed at the top of the soil bin, including computer, object board, and angle steel, which is responsible for collecting data and controlling each device compiled by software.

After the equipment connection is completed, the bionic sample is placed in the soil bin and the moving speed, the flow rate, and the number and position of the peristaltic pump are set up by the control software, and then the motor is started. The lead screw moves the bionic sample forward, and the data acquisition is transmitted to the computer by the data collector in actual time. The force sensor is Kistler Triaxial Force Sensor Type 9027C and assembly located and fixed between the traction rope and moving plate. The test image and the data can be obtained by software. For the testing procedure, see Figure 4(b).

\section{Test and Result Analysis}

3.1. Single Factor Test and Result Analysis. Forward velocity, flow rate of lubricating fluid, and normal pressure are important factors affecting forward resistance. In order to investigate their effects, a single factor test was carried out when soil moisture content was $22.2 \%$ with lubrication and 


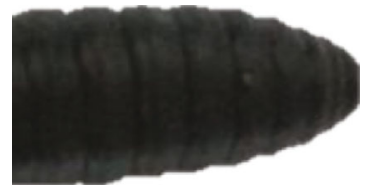

(a) Surface specimen of earthworm

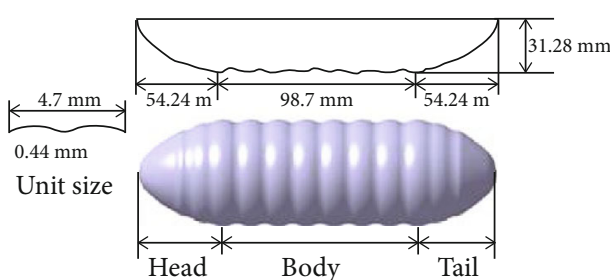

(b) Bionic specimen

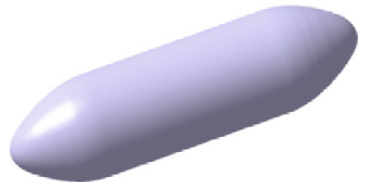

(c) Smooth contrast specimen

Figure 1: Specimen.

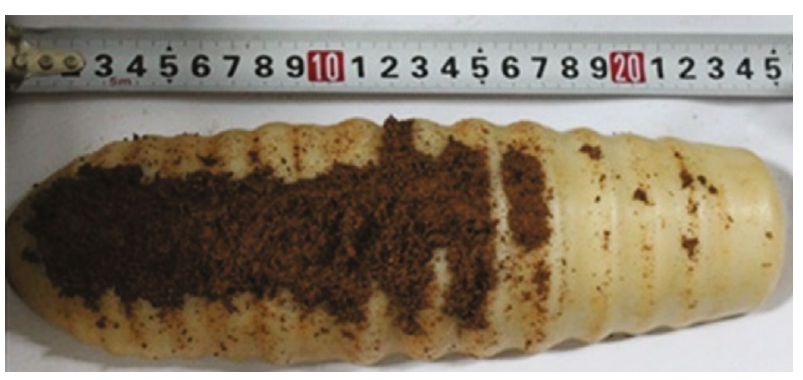

FIgURE 2: Adhesion when normal pressure was $34 \mathrm{~N}$.

TABLE 1: Adhesive quality of different parts.

\begin{tabular}{lcccc}
\hline $\begin{array}{l}\text { Normal } \\
\text { pressure }(\mathrm{N})\end{array}$ & $\begin{array}{c}\text { Head } \\
\text { adhesion } \\
(\mathrm{g})\end{array}$ & $\begin{array}{c}\text { Body } \\
\text { adhesion } \\
(\mathrm{g})\end{array}$ & $\begin{array}{c}\text { Tail } \\
\text { adhesion } \\
(\mathrm{g})\end{array}$ & $\begin{array}{c}\text { Total } \\
\text { adhesion } \\
(\mathrm{g})\end{array}$ \\
\hline 17 & 7.4 & 6.53 & 0.29 & 14.22 \\
34 & 13.83 & 6.95 & 0.09 & 20.87 \\
51 & 16.21 & 9.58 & 0.22 & 26.01 \\
68 & 19.36 & 13.17 & 0.46 & 32.99 \\
85 & 28.02 & 14.44 & 0.12 & 42.58 \\
\hline
\end{tabular}

nonlubrication, and three repeated tests were carried out to reduce the error. The test plan is shown in Table 2 .

The effect of forward velocity on forward resistance is shown in Figure 5(a) when the normal pressure is $34 \mathrm{~N}$ and the flow rate of lubricating fluid is $0.06 \mathrm{ml} / \mathrm{s}$. From Figure 5(a), it can be seen that the forward resistance is between $26.32 \mathrm{~N} \sim 33.14 \mathrm{~N}$ without lubrication and $18.11 \mathrm{~N} \sim 23.46 \mathrm{~N}$ with lubrication, and the drag reduction rate is $24.19 \%$ to $33.71 \%$. In addition, the forward resistance decreases with the increase of the forward speed under both lubricated and nonlubricated conditions. Without lubrication, it decreases obviously with the increase of velocity, because when the velocity is small, the contact time between corrugated body surface and soil becomes longer and the disturbance to the soil increases in the course of movement. With lubrication, the forward resistance of $500 \mathrm{~cm} / \mathrm{min}$ is greater than that of $400 \mathrm{~cm} / \mathrm{min}$, which is due to that the fluid cannot penetrate the interface between corrugated surface and soil sufficiently with the increase of velocity, resulting in a reduced lubrication effect.

When the forward velocity is $300 \mathrm{~cm} / \mathrm{min}$, and the flow rate of lubricating fluid is $0.06 \mathrm{ml} / \mathrm{s}$, the effect of normal pressure on the forward resistance is shown in Figure 5(b). From Figure 5(b), it can be seen that the forward resistance is $18.01 \mathrm{~N} \sim 70.08 \mathrm{~N}$ without lubrication and 11.23 $\mathrm{N} \sim 48.47 \mathrm{~N}$ with lubrication, and the drag reduction rate is $36.27 \% \sim 58.46 \%$. With the increase of normal pressure, the reducing effect is more and more obvious, and the forward resistance of unlubricated and lubricated conditions will increase continuously, because the contact area between corrugated surface and soil increases with the increase of normal pressure, and the gap between corrugated surface and soil decreases, which make soil compacted and the friction resistance increased.

When the normal pressure is $34 \mathrm{~N}$ and the forward velocity is $300 \mathrm{~cm} / \mathrm{min}$, the effect of the flow rate of lubricating fluid on the forward resistance is shown in Figure 5(c). From Figure 5(c), it can be seen that the forward resistance decreases first and then remains unchanged with the increase of the flow rate of the lubricating fluid. When the velocity rate is $0.08 \mathrm{ml} / \mathrm{s}$, the forward resistance is $21.32 \mathrm{~N}$ that is close to $20.09 \mathrm{~N}$ when the rate is $0.1 \mathrm{ml} / \mathrm{s}$. This is because with the increase of the flow rate of the lubricating fluid, the fluid fully permeates into the contact interface between corrugated surface and soil and then forms the interfacial lubrication, making the resistance decrease. When it increases to a certain condition, the interface water film is saturated, so the forward resistance is almost unchanged.

3.2. Ternary Quadratic Regression Combination Test and Result Analysis. In order to further explore the effect of these three factors and establish the equation between forward resistance and each factor, the three-element quadratic regression combination test [27] was carried out, and the repeated test with $m_{0}=3, r^{2}=1.831$ was selected. The factor level and coding are shown in Table 3.

According to the testing requirements and the designing principle of quadratic regression orthogonal, the experimental scheme is worked out and the regression coefficients and squares of each sequence are calculated as shown in Table 4.

By testing the regression coefficient, the equation is obtained as follows:

$$
\begin{aligned}
\hat{y}= & 16.10+5.68 x_{1}-0.81 x_{2}-1.29 x_{3} \\
& +1.61 x_{1}{ }^{2}-0.96 x_{2}{ }^{2}-0.23 x_{3}{ }^{2} .
\end{aligned}
$$

Therefore, the sum of regressing squares is

$$
\begin{aligned}
& S_{\text {回 }}=S_{x_{1}}+S_{x_{2}}+S_{x_{3}}+S_{x_{1}^{\prime}}+S_{x_{2}^{\prime}}+S_{x_{3}^{\prime}}=287.69, \\
& f_{\text {回 }}=6 .
\end{aligned}
$$




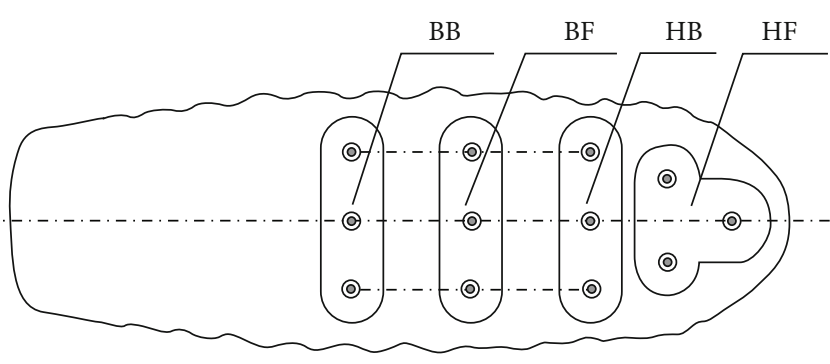

(a) Lubricating hole design

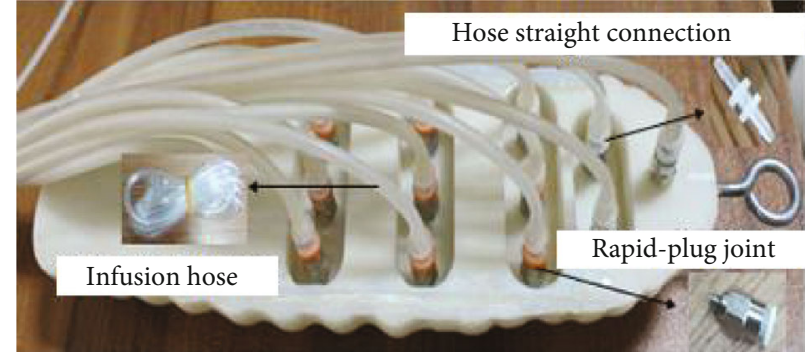

(b) Physical drawing

Figure 3: Coupling bionic specimen.

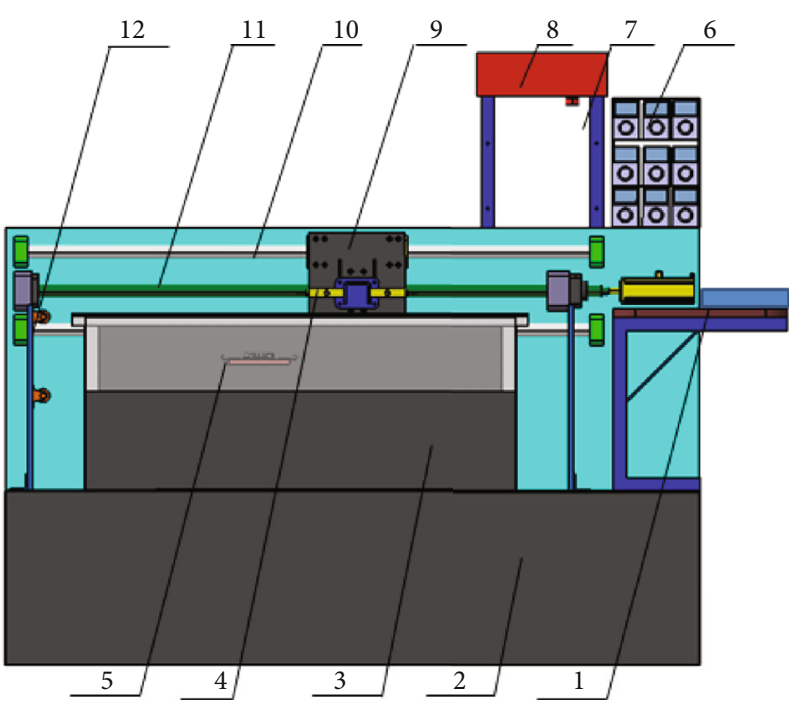

(a) Structure diagram of the test equipment

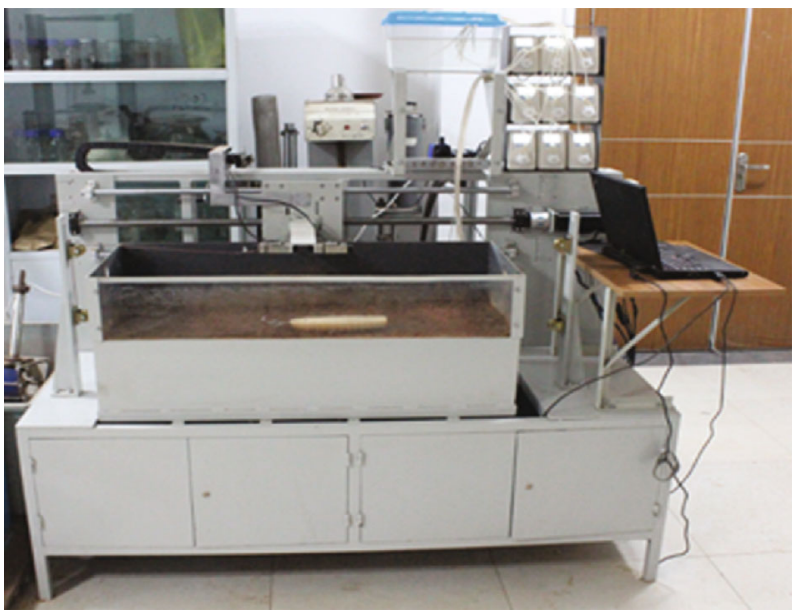

(b) Testing procedure

FIGURE 4: Test and equipment. 1: data acquisition device, 2: support frame, 3: soil bin, 4: force sensor, 5: bionic sample, 6: peristaltic pump, 7: lubricating adjustment device, 8: water tank, 9: moving plate, 10: motion control device, 11: screw drive set, 12: pulley block.

Table 2: Single factor test scheme.

\begin{tabular}{lccc}
\hline Level & $\begin{array}{c}\text { Forward velocity } \\
(\mathrm{cm} / \mathrm{min})\end{array}$ & $\begin{array}{c}\text { Flow rate of lubricating } \\
\text { fluid }(\mathrm{ml} / \mathrm{s})\end{array}$ & $\begin{array}{c}\text { Normal } \\
\text { pressure }(\mathrm{N})\end{array}$ \\
\hline 1 & 100 & 0.01 & 17 \\
2 & 200 & 0.02 & 34 \\
3 & 300 & 0.03 & 51 \\
4 & 400 & 0.04 & 68 \\
5 & 500 & 0.05 & 85 \\
\hline
\end{tabular}

Because

$$
\begin{aligned}
& S=\sum_{i=1}^{13} y_{i}^{2}-\frac{1}{13}\left(\sum_{i=1}^{17} y_{i}\right)^{2}=293.24, \\
& f=12, \\
& s_{R}=s-s_{\text {回 }}=5.55, \\
& f_{R}=6,
\end{aligned}
$$

$$
\begin{aligned}
s_{e} & =\sum_{i=1}^{17}\left(y_{i 0}-\overline{y_{0}}\right)=0.93, \\
f_{e} & =2, \\
s_{e} & =\sum_{i=1}^{17}\left(y_{i 0}-\overline{y_{0}}\right)=0.93, \\
f_{l f} & =4 .
\end{aligned}
$$

So

$$
\begin{gathered}
F_{\text {回 }}=\frac{s_{\text {回 }} / f_{\text {回 }}}{s_{R} / f_{R}}=51.83>F(6,6)=8.47, \\
F_{l f}=\frac{s_{l f} / f_{l f}}{s_{e} / f_{e}}=2.97<F_{0.25}(4,2)=3.23 .
\end{gathered}
$$

The statistical test results show that the significant level of the equation is 0.01 and the fitting is very good, which can be considered as the best regression equation. The central processing and coding formula of the factors in the table are 


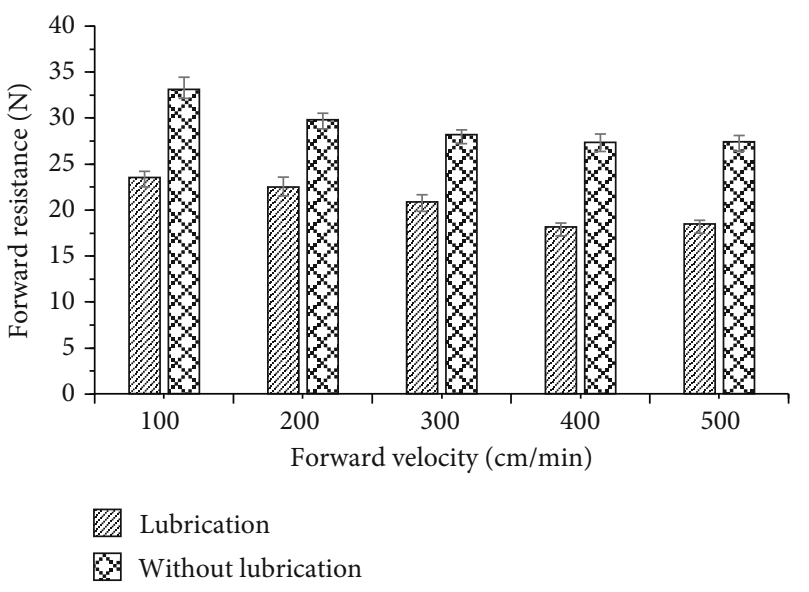

(a) The effect of forward velocity on forward resistance

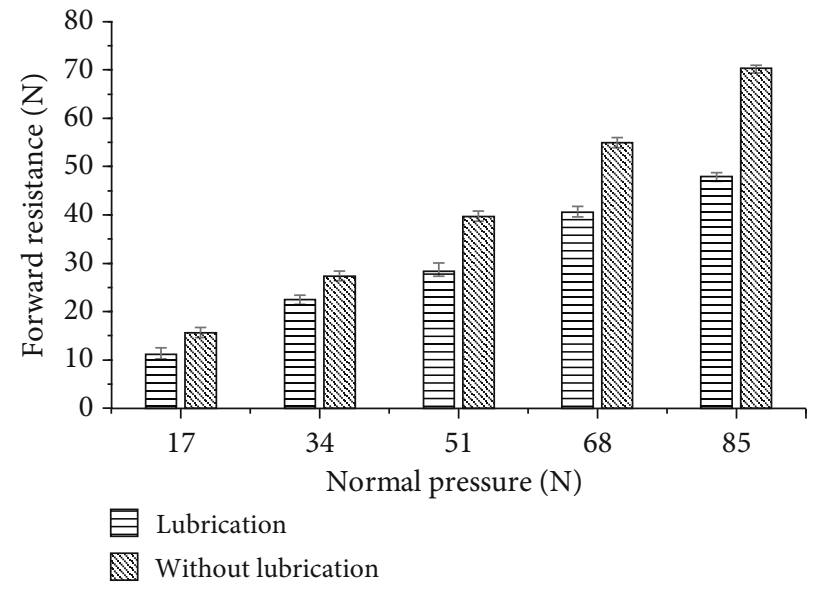

(b) The effect of normal pressure on forward resistance

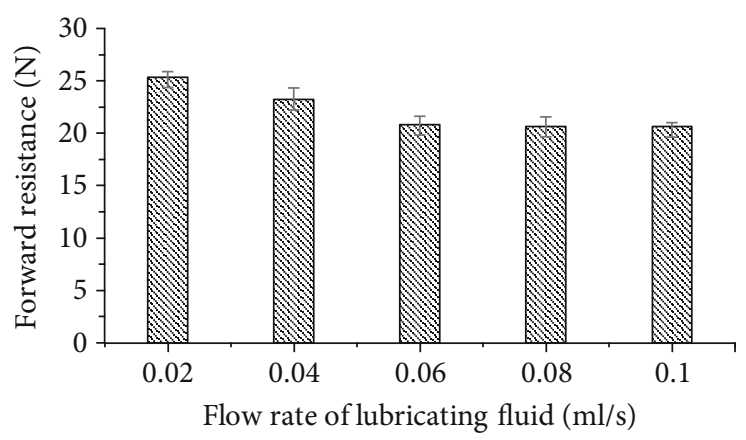

(c) The effect of flow rate of lubricating fluid on forward resistance

Figure 5: Results of a single factor test.

TABLE 3: Natural factor level and its coding table.

\begin{tabular}{lccc}
\hline$x_{j}\left(z_{j}\right)$ & $Z_{1}(\mathrm{~N})$ & $Z_{2}(\mathrm{ml} / \mathrm{s})$ & $Z_{3}(\mathrm{~cm} / \mathrm{min})$ \\
\hline$r$ & 51 & 0.1 & 500 \\
1 & 46.56 & 0.09 & 447.82 \\
0 & 34 & 0.06 & 300 \\
1 & 21.44 & 0.03 & 152.18 \\
$-r$ & 17 & 0.02 & 100 \\
$\Delta_{j}=\frac{z_{2 j}-z_{1 j}}{2 r}$ & 12.56 & 0.03 & 147.82 \\
$x_{j}=\frac{z_{j}-z_{0 j}}{\Delta_{j}}$ & $x_{1}=0.076 \times\left(z_{1}-34\right)$ & $x_{2}=33.33 \times\left(z_{1}-0.06\right)$ & $x_{3}=0.006 \times\left(z_{1}-300\right)$ \\
\hline
\end{tabular}

Note: $Z_{1}$ means normal pressure; $Z_{2}$ means flow rate of lubricating fluid; $Z_{3}$ means forward velocity.

put into equation (1) and the regression equation is obtained as follows:

$$
\begin{aligned}
y= & 12.21+0.2 z_{1}+100.98 z_{2}-0.0028 z_{3} \\
& +0.0093 z_{1}^{2}-1066.45 z_{2}^{2}+8.28 \times 10^{-6} z_{3}^{2} .
\end{aligned}
$$

By testing the regression coefficient of formula (1), it is found that the order of the test factors affecting the forward resistance is as follows: normal pressure $>$ flow rate of lubri- cating fluid $>$ forward velocity, and the three factors have a significant effect on the forward resistance.

From formula (9), we can see that normal pressure $Z_{1}$, flow rate of lubricating fluid $Z_{2}$, and forward velocity $Z_{3}$ have a secondary effect on the forward resistance, but there is no interaction between them, as shown in Figure 6 .

\section{Conclusion}

We can conclude the following: 
TABle 4: Orthogonal rotation combination test plan and results.

\begin{tabular}{lllcccccc}
\hline & $X_{0}$ & $X_{1}\left(z_{1}\right)$ & $X_{2}\left(z_{2}\right)$ & $X_{3}\left(z_{3}\right)$ & $X_{1}{ }^{2}\left(X_{1}{ }^{\prime}\right)$ & $X_{2}{ }^{2}\left(X_{2}{ }^{\prime}\right)$ & $X_{3}{ }^{2}\left(X_{3}{ }^{\prime}\right)$ & $Y_{i}$ \\
\hline 1 & 1 & 1 & 1 & 1 & 1 & 1 & 1 & 20.09 \\
2 & 1 & 1 & -1 & -1 & 1 & 1 & 1 & 22.64 \\
3 & 1 & -1 & 1 & -1 & 1 & 1 & 1 & 9.84 \\
4 & 1 & -1 & -1 & 1 & 1 & 1 & 1 & 10.14 \\
5 & 1 & $r$ & 0 & 1 & $r^{2}$ & 0 & 0 & 26.96 \\
6 & 1 & $-r$ & 0 & 0 & $r^{2}$ & 0 & 0 & 11.6 \\
7 & 1 & 0 & $r$ & 0 & 0 & $r^{2}$ & 0 & 13.65 \\
8 & 1 & 0 & $-r$ & 0 & 0 & $r^{2}$ & 0 & 16.18 \\
9 & 1 & 0 & 0 & $r$ & 0 & 0 & $r^{2}$ & 13.53 \\
10 & 1 & 0 & 0 & $-r$ & 0 & 0 & $r^{2}$ & 18.78 \\
11 & 1 & 0 & 0 & 0 & 0 & 0 & 0 & 15.35 \\
12 & 1 & 0 & 0 & 0 & 0 & 0 & 0 & 15.21 \\
13 & 1 & 0 & 0 & 0 & 0 & 0 & 0 & 15.39 \\
$D_{j}$ & 13 & 7.66 & 7.66 & 7.66 & 6.19 & 6.19 & 6.19 & -1.44 \\
$B_{j}$ & 209.36 & 43.53 & -6.27 & -9.95 & 10 & -5.98 & -0.23 & \\
$b_{j}$ & 16.10 & 5.68 & -0.81 & -1.29 & 1.61 & -0.96 & 0.33 & \\
$S_{j}$ & 3371.66 & 247.37 & 5.13 & 12.92 & 16.16 & 5.78 & 646.93 & 37.51 \\
$F_{j}$ & & 27701.11 & 574.72 & 1447.32 & 1809.08 & 0.01 & 0.05 & \\
$\alpha_{j}$ & & 0.01 & 0.01 & 0.01 & 0.01 & 0.01 & \\
\hline
\end{tabular}

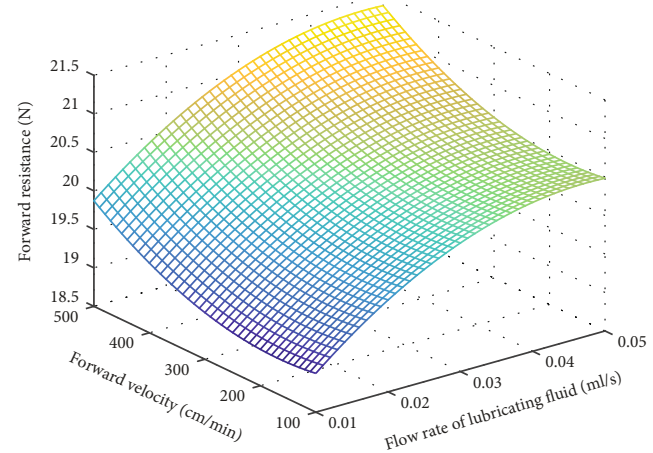

(a) $Z_{1}=17 \mathrm{~N}$

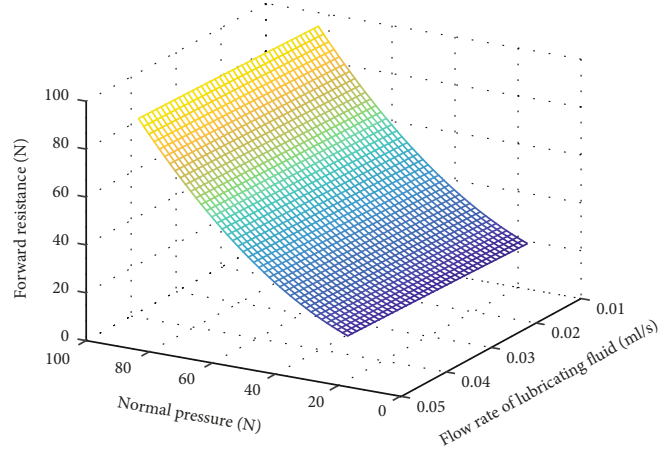

(b) $Z_{2}=0.05 \mathrm{ml} / \mathrm{s}$

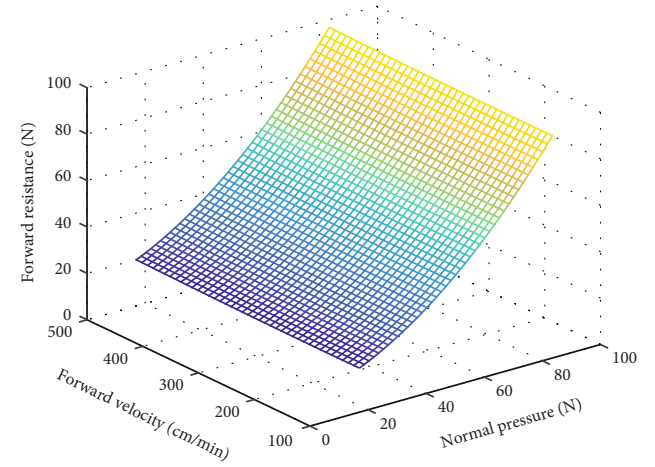

(c) $Z_{3}=100 \mathrm{~N}$

Figure 6: Results of orthogonal rotation combination test. 
(1) Based on the reverse engineering method, earthworm corrugated curves are extracted; bionic samples matched with real earthworm's body surface are designed. The bionic sample was printed by $3 \mathrm{D}$ printing, the location of lubricating hole was determined by the experiment method, and the bionic coupling of corrugated self-lubrication was realized

(2) A test rig was designed and developed to test the lubricating drag reduction performance of soilengaging components, which can accurately control the flow rate of lubricating fluid and measure the forward resistance of the sample quickly

(3) The results of a single factor test show that the drag reduction of the bionic coupling sample is obvious, the drag reduction rate is $22.65 \%-34.89 \%$, and the forward resistance decreases with the increase of forward velocity, which is proportional to the normal pressure, and at the same time, when the flow rate of lubricating fluid increases gradually, the forward resistance decreases first and then tends to stabilize

(4) The regression equations between forward resistance and normal pressure, flow rate of lubricating fluid, and the forward velocity of the bionic coupling sample were obtained by using the ternary quadratic regression combination test. The regression analysis shows that the three factors have secondary effects on the forward resistance, and the order is as follows: normal pressure $>$ flow rate of lubricating fluid $>$ forward velocity, but there was no interaction between them

\section{Data Availability}

We have submitted the raw data used in our manuscript and the other supplementary date are shown in the attachment. Other researchers can access the data supporting the conclusions of the study. (1) The nature of the data is the source data of the image in the paper; (2) the data can be accessed on the submitting system or through email to zoumeng@jlu.edu.cn; (3) there are no restrictions on the data access.

\section{Disclosure}

The results were originally presented at ICBE2019.

\section{Conflicts of Interest}

No potential conflict of interest was reported by the authors.

\section{Acknowledgments}

This project is supported by the National Natural Science Foundation of China Youth Science Foundation (Grant No. 5140051354). The project is also supported from China Scholarship Council (CSC) for the first author's scholarship.

\section{References}

[1] L. Q. Ren, D. X. Chen, and B. C. Chen, "A summary of study on soil adhesion," Transactions of the CSAE, vol. 6, no. 1, pp. 1-7, 1990.

[2] L. Q. Ren, J. Tong, J. Q. Li, and B. C. Chen, "Biomimetics of machinery for soft terrain," Transactions of the Chinese Society for Agricultural Machinery, vol. 31, no. 1, pp. 5-9, 2000.

[3] L. Q. Ren, "The progress of the research on terrain-machine bionics of reducing soil adhesion," Science in China Series E: Technological Sciences, vol. 38, pp. 1353-1364, 2008.

[4] L. Q. Ren, J. Tong, J. Q. Li, and B. C. Chen, "Soil adhesion and biomimetics of soil-engaging components: a review," Journal of Agricultural Engineering Research, vol. 79, no. 3, pp. 239263, 2001.

[5] T. Shelley, "Lubrication-Worms show way to efficiently moveTom Shelley reports on an animal-inspired way to improve the efficiency of agricultural equipment," Eureka-Innovative Engineering Design, vol. 24, no. 1, pp. 28-29, 2004.

[6] Y. Lu, "Significance and progress of bionics," Journal of Bionic Engineering, vol. 1, no. 1, pp. 1-3, 2004.

[7] A. Q. Li, L. Q. Ren, B. C. Chen, and X. X. Cui, "Constitution and mechanism analysis of reducing soil adhesion for the body surface liquid of earthworms," Transactions of The Chinese Society of Agricultural Engineering, vol. 6, no. 3, pp. 8-14, 1990.

[8] J. R. Sun, B. N. Sun, J. H. Wei et al., "Measurement and determination earthworm skin potential related to moving," Journal of Jilin University of Technology, vol. 21, no. 4, pp. 18-24, 1991.

[9] L. Q. Ren, Q. Cong, L. K. Wu, and D. X. Chen, "Study on the reduction of soil adhesion and resistance by the application of non smooth surface electroosmosis," Transactions of The Chinese Society of Agricultural Engineering, vol. 11, no. 3, pp. 24-28, 1995.

[10] Q. Cong, L. K. Wu, L. Q. Ren, and B. Chen, “The principled experiment of reducing soil adhesion and scouring soil by nonsmooth surface electroosmosis," Transactions of the Chinese Society of Agricultural Engineering, vol. 11, no. 3, pp. 19-23, 1995.

[11] L. Q. Ren, Y. P. Wang, J. Q. Li, and S. Sun, "Bionic research on flexible nonsmooth surface of typical animals," Transactions of the Chinese Society of Agricultural Engineering, vol. 12, no. 4, pp. 31-36, 1996.

[12] Z. J. Zhao, Bionic study on the mechanism of reducing adhesion and desorption of earthworms, Peking University, Beijing, 2004.

[13] J. R. Sun and Z. D. Dai, "Non-smooth surface bionics(II)," Journal Advances in Natural Sciences, vol. 18, no. 7, pp. 727733, 2008.

[14] G. M. Liu, J. Q. Li, X. M. Tian, M. Zou, and Y. Li, “Experiment on reduction of soil adhesion force and sliding resistance of earthworm non-smooth surface," Transactions of the Chinese Society for Agricultural Machinery, vol. 39, no. 9, pp. 138143, 2008.

[15] J. Q. Li, B. X. Kou, G. M. Liu, W. Fan, and L. Liu, "Resistance reduction by bionic coupling of the earthworm lubrication function," Science China Technological Sciences, vol. 53, no. 11, pp. 2989-2995, 2010.

[16] W. P. Shi, L. Q. Ren, and Y. Y. Yan, "The creeping mechanism of the non-smooth wavy surface of earthworm body," Chinese 
Journal of Mechanics and Engineering, vol. 27, no. 3, pp. 73-74, 2005.

[17] Y. Q. Zu and Y. Y. Yan, "Numerical simulation of electroosmotic flow near earthworm surface," Journal of Bionic Engineering, vol. 3, no. 4, pp. 179-186, 2006.

[18] Y. Y. Yan, Y. Q. Zu, L. Q. Ren, and J. Q. Li, "Numerical modeling of electro-osmotically driven flow within the microthin liquid layer near an earthworm surface-a biomimetic approach," Proceedings of the Institution of Mechanical Engineers, Part C: Journal of Mechanical Engineering Science, vol. 221, pp. 1201-1209, 2007.

[19] Y. Zhang, C. H. Zhou, and L. Q. Ren, "Biology coupling characteristics on soil-engaging components of mole crickets," Journal of Bionic Engineering, vol. 5, Suppl 1, pp. 164-171, 2008.

[20] L. Q. Ren and Y. H. Liang, "Biological couplings: classification and characteristic rules," Science in China Series E: Technological Sciences, vol. 40, no. 1, pp. 5-13, 2010.

[21] L. H. Shu, K. Ueda, and I. Chiu, "Biologically inspired design," CIRP Annals - Manufacturing Technology, vol. 60, pp. 673693, 2011.

[22] D. Zhang, Y. Chen, Y. Ma, G. Li, J. Sun, and J. Tong, "Earthworm epidermal mucus: rheological behavior reveals dragreducing characteristics in soil," Soil and Tillage Research, vol. 158, pp. 57-66, 2016.

[23] Y. Q. Gu, T. X. Fan, J. G. Mou, L. F. Jiang, D. H. Wu, and S. H. Zheng, "A review of bionic technology for drag reduction based on analysis of abilities the earthworm," International Journal of Engineering Research in Africa, vol. 19, pp. 103111, 2016.

[24] G. M. Liu, Coupling bionic research on the adhesion and resistance reduction of the earthworm surface, Jilin University, Changchun, China, 2009.

[25] Y. Q. Gu, J. G. Mou, D. S. Dai et al., "Characteristics on drag reduction of bionic jet surface based on earthworm's back orifice jet," Acta Physica Sinica, vol. 64, no. 2, pp. 306-315, 2015.

[26] Y. Gu, J. Mu, S. Zheng, G. Zhao, J. Ru, and C. G. Wang, "Effect of jet hole arrangement on drag reduction characteristics of jet surface," Transactions of the Chinese Society for Agricultural Machinery, vol. 45, no. 10, pp. 340-346, 2014.

[27] L. Q. Ren, Optimum design and analysis of experiments, L. Ren, Ed., Higher Education Press, Beijing, 2003. 


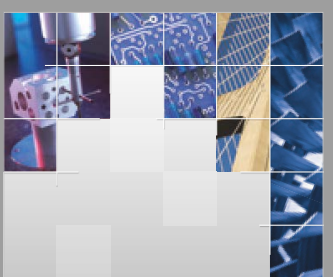

\section{Enfincering}
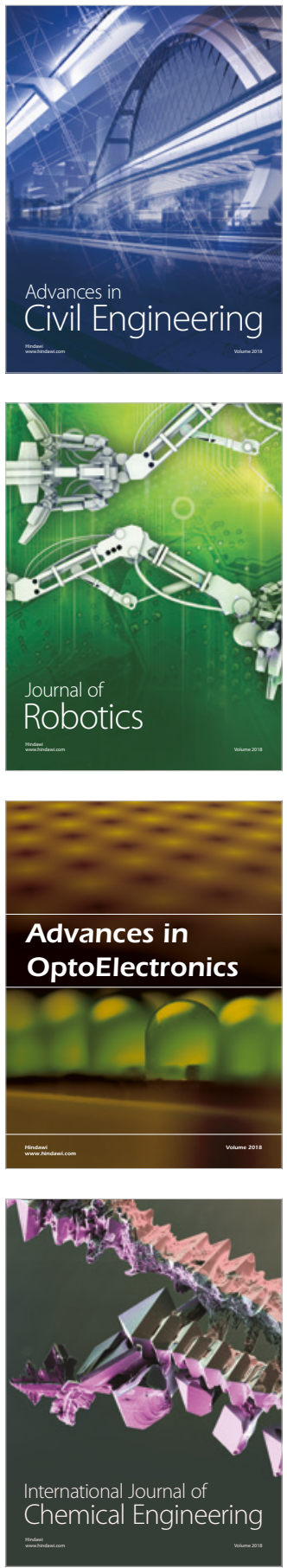

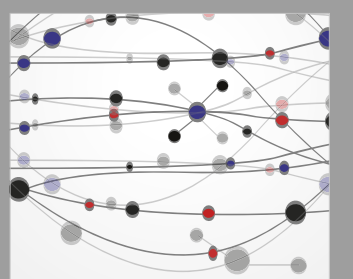

\section{Rotating \\ Machinery}

The Scientific World Journal

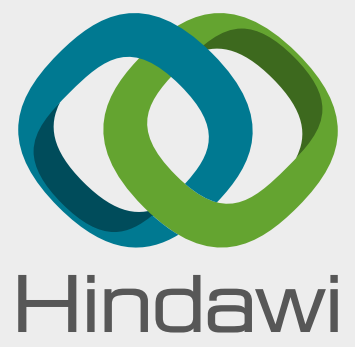

Submit your manuscripts at

www.hindawi.com
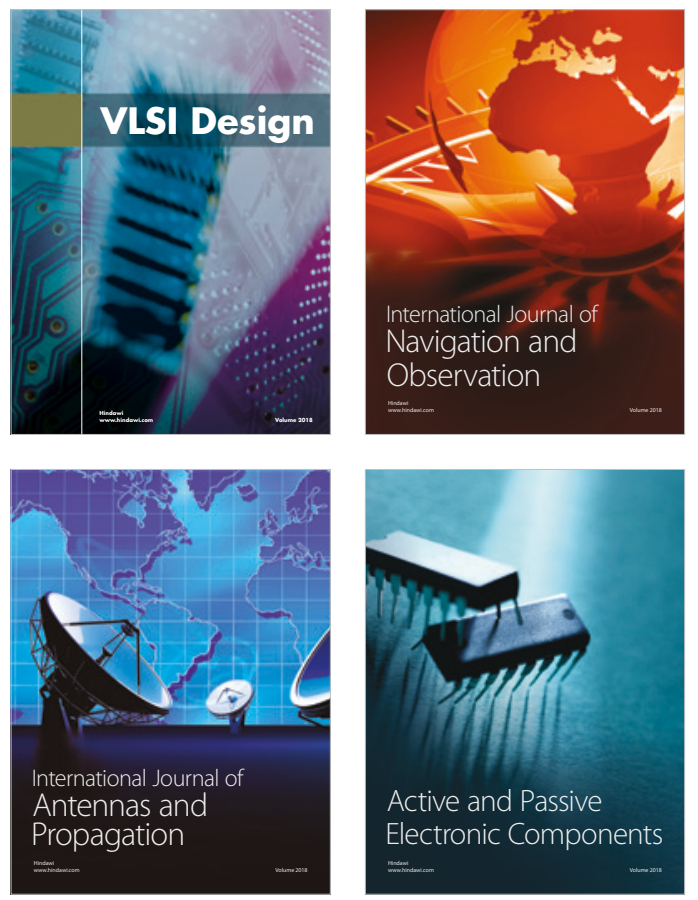
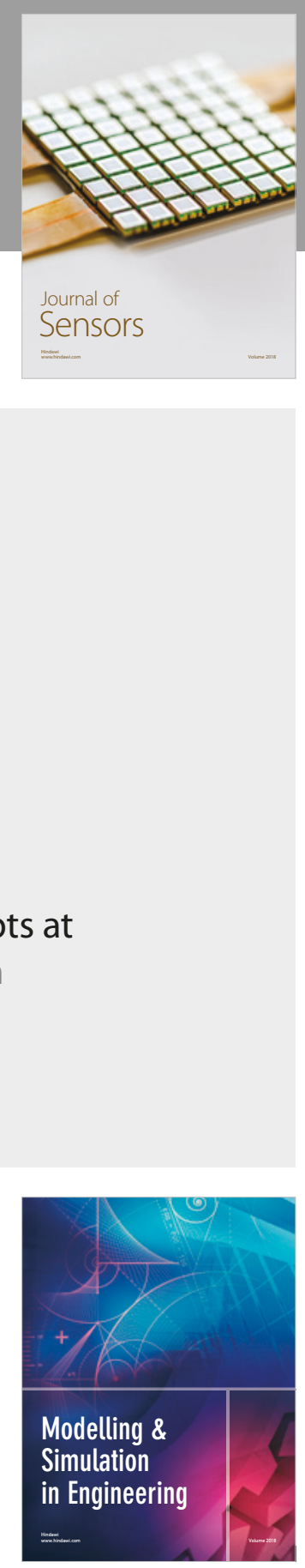

\section{Advances \\ Multimedia}
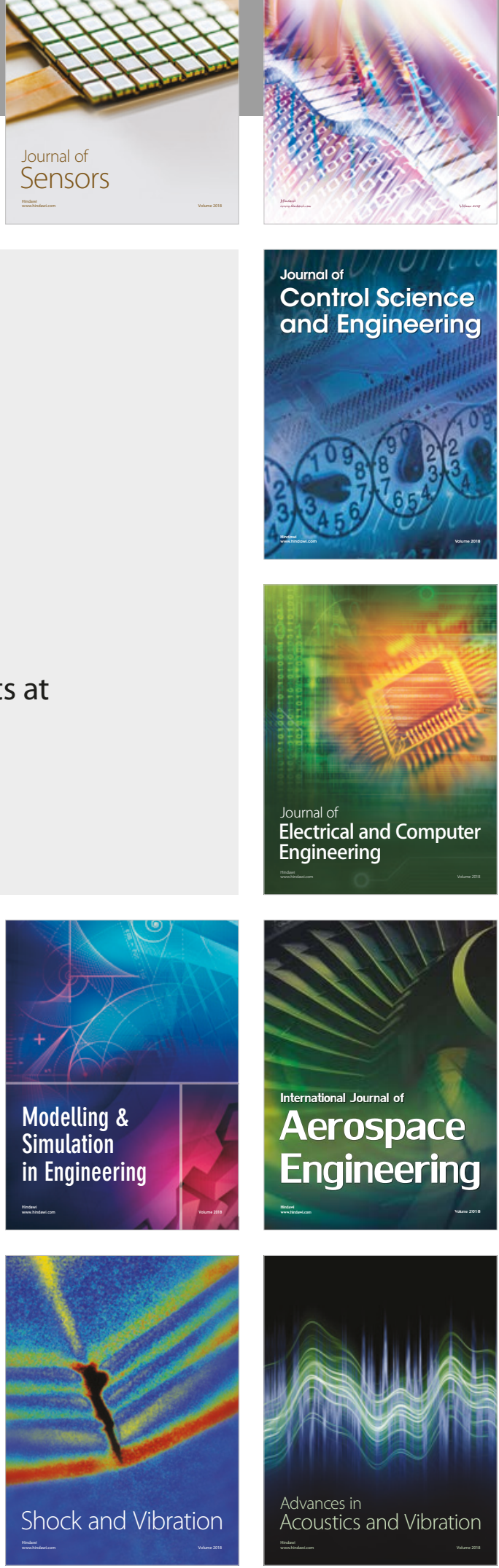